\title{
Illuminating Social Justice in the Framework: Transformative Methodology, Concept Mapping and Learning Outcomes Development for Critical Information Literacy
}

Nicole A. Branch

Santa Clara University, nbranch@scu.edu

Follow this and additional works at: https://pdxscholar.library.pdx.edu/comminfolit

Part of the Information Literacy Commons

Let us know how access to this document benefits you.

\section{Recommended Citation}

Branch, N. A. (2019). Illuminating Social Justice in the Framework: Transformative Methodology, Concept Mapping and Learning Outcomes Development for Critical Information Literacy. Communications in Information Literacy, 13 (1), 4-22. https://doi.org/10.15760/comminfolit.2019.13.1.2

This open access Research Article is distributed under the terms of the Creative Commons AttributionNonCommercial-ShareAlike 4.0 International License (CC BY-NC-SA 4.0). All documents in PDXScholar should meet accessibility standards. If we can make this document more accessible to you, contact our team. 


\title{
Illuminating Social Justice in the Framework: Transformative Methodology, Concept Mapping, and Learning Outcomes Development for Critical Information Literacy
}

\author{
Nicole A. Branch, Santa Clara University
}

Abstract

The intentional omission of learning outcomes from the ACRL Framework for Information Literacy in Higher Education has caused concern and criticism from some librarians; however, the call to action within the Framework to locally develop learning outcomes is an opportunity to illuminate the social justice, critical thinking, and higher order thinking elements of information literacy. This study applies the transformative research paradigm using the methodology of concept mapping to test the development of learning outcomes for one of the frames. Concept mapping is a mixed-methods approach and includes focus groups, hierarchical cluster analysis, and multidimensional scaling. The methodology has been used extensively in the social sciences but has limited representation in the LIS literature. Though the study provides learning outcomes developed by a small participant group following the concept mapping method, the results demonstrate the viability of this methodology for librarians seeking a new approach to locally develop learning outcomes. Keywords: information literacy, critical information literacy, transformative methodology, assessment, learning outcomes

\section{Research Articles edited by Christopher V. Hollister \& April Schweikhard}

Branch, N.A. (2019). Illuminating social justice in the Framework: Transformative methodology, concept mapping, and learning outcomes development for critical information literacy Communications in Information Literacy, 13(1), 4-22.

Copyright for articles published in Communications in Information Literacy is retained by the author(s). Author(s) also extend to Communications in Information Literacy the right to redistribute this article via other scholarly resources and bibliographic databases. This extension allows the authors' copyrighted content to be included in some databases that are distributed and maintained by for-profit companies. All other rights of redistribution are licensed by Communications in Information Literacy under Creative Commons Attribution-NonCommercial-ShareAlike 4.0 International (CC BYNC-SA 4.0).

Branch

Illuminating Social Justice in the Framework

[ RESEARCH ARTICLE ] 


\section{Introduction}

This study demonstrates how the transformative research paradigm-and concept mapping methodology—can be used to develop learning outcomes that illuminate the social justice, critical thinking, and higher order thinking elements of information literacy.

Transformative approaches explicitly tie research methods and practices to social justice and are in alignment with critical librarianship practices. Concept mapping presents a way to practically implement these approaches. The concept mapping methodology employed for this study is a form of mixed-methods research that allows for collaborative development and synthesis of a concept. In this application, participants explored "Information Has Value" as a concept by developing learning outcomes for this information literacy frame. This study demonstrates that transformative paradigms can be used to engage librarians and stakeholders in developing learning outcomes that are vital and meaningful by providing a structure for collaborative visioning.

\section{Literature Review}

Context

The drafting and subsequent adoption of the Association of College and Research Libraries (ACRL) Framework for Information Literacy in Higher Education (2015), referred to as the Framework and frames, has brought to the forefront a number of concerns among librarians. Librarians dedicated to critical approaches and social justice assert that the Framework and our assessment methods have not gone far enough or deep enough regarding social justice. Critical information literacy, first introduced by Elmborg in 2006, draws on critical literacy theory and critical pedagogy to advance orientations to information literacy that seek to raise the critical consciousness of learners. Tewell (2015) provided a comprehensive review of the development of critical information literacy over the last decade, demonstrating the prominent adoption of critical practices by librarians. Critical theories were applied to critiques of the Framework, exemplified by Battista et al. (2015). These authors critiqued the Framework for not reaching far enough to address civic engagement and cultural orientations to information, noting the primarily skills-based nature of the knowledge practices and dispositions of the Framework. They went on to propose that librarians continue to explore and create explicit social justice frames, such as "Information as a Human Right." 
Another set of concerns about both the Framework and the sunsetting of the Information Literacy Competency Standards for Higher Education (ACRL, 2000), referred to as the Standards, was distilled in the January 2015 open letter from a group of librarians (Dalal, 2015). Included in these concerns was the perceived need to maintain codified and universal standards, the potential loss of political power where the Standards had been integrated into professional association or accrediting agency standards, and the concern that the frames are overly theoretical, and thus cannot be assessed. These expressed concerns illustrate interrelated perspectives on and critiques of the assessment of information literacy. First, several authors have noted that academic libraries gain and maintain institutional power, in part, through professionally sanctioned standards (Drabinski \& Sitar, 2016) and a uniform set of learning outcomes (Dalal, 2015; Dempsey, Dalal, Dokus, Charles, \& Scharf, 2015). Secondly, authors both within and outside of library science have questioned the current state of assessment practices in higher education, including the concerns that assessment would not be useful or would assess things that educators do not truly need to know (Accardi, 2009; Gardner \& Halpern, 2016) and that assessment has increasingly become a component of neoliberalism in higher education (Gardner \& Halpern, 2016; Wall, Hursh, \& Rodgers, 2014).

At the same time, librarians have voiced optimism-and calls to action-suggesting the Framework has the potential to empower and transform library educators' approach to instruction and assessment. Pagowsky (2015) advocated for harnessing the sometimes uncomfortable ways that the Framework has pushed library educators to re-imagine how they teach in the face of neoliberalism in higher education. Pagowsky posited that the Framework can support librarians to engage in "fabulation," a literary term that can be understood as "an approach to reimagining in-place systems and structures in order to create change and turn these imaginings into reality" (p. 141). Pagowsky suggested that the Framework offers an opportunity to "fabulate"-or reimagine and create anew-information literacy pedagogy, the role of librarians as educators, and the perceptions and expectations of library instruction. The Framework thus provides a juncture to advance not only information literacy pedagogy, but the library educator's identity within the academy.

Foasberg (2015) argued that the Standards and the Framework are so divergent in their theoretical underpinnings that librarians must resist the urge to simply transpose the Standards onto the frames. Foasberg's critical examination asserted these fundamental differences: the Standards emphasize information literacy skills and abilities and information

Branch 
as a commodity, while the Framework approaches information literacy as a social, relational, and contextual set of practices and information as not a static product but rather a "social phenomenon" (p. 702). Foasberg saw both the potential for reimagining what the Framework presents as well as the need to further develop our practice. For these reasons, both Foasberg and Pagowsky suggested that truly embracing the opportunities provided by the Framework to re-envision the educational mission of library educators could be seen as a radical push-back and an assertion of the librarian's role in the reclamation of higher education against neoliberal agendas.

This critique of the Standards has been echoed in broader critiques of assessment in higher education. Wall et al. (2014) provided a concise overview of the development of assessment practices in higher education over the past two decades, concluding that assessment had largely become a "managerial administrative practice heavily influenced by neoliberal ideology" (p. 5). These authors argued that assessment practices had come to focus on commodifying learning for the global capitalist market, rather than measuring the central purpose of higher education to serve the common good. They went on to advance a vision of "assessment as an ethical and valuing social practice" (p. 10). This conception of assessment requires centering the evaluation process through an ethical frame, a transparency of purpose, a clear identification of stakeholders, an alignment of ethical stances and methods, and a strong interpretation of findings.

After the adoption of the Framework, Oakleaf (2014) provided a roadmap for assessing the Framework. Oakleaf argued that the frames are not only assessable, but well-suited to learning outcomes assessment. Though Oakleaf addressed the need for inspiration, it was but one of the outlined practices for learning outcome development. While this roadmap was a good overview of learning outcomes development, it largely addressed logistical components. This study specifically approached the challenge of assessing the frames not as a problem of understanding practical steps, but as a crisis of inspiration, identity, and empowerment. By adopting concrete methods to address this challenge, library instructors can rise to new levels of practice. Through this study, the author explored concept mapping methodology as a concrete way that library educator's might, as Pagowsky (2015) suggested, "transcend our pedagogy and our identity-constricted by social, economic, and political orders-to instead shape how we could teach rather than being stuck on how we are expected to teach" (p. 141). This study explored the development of learning outcomes for the Framework that (a) are viable learning outcomes; (b) address critical information literacy 
and higher order thinking; and (c) provide new ways to envision our roles, our pedagogy, and student learning.

This study was designed to explore a specific process and to suggest theoretical and methodological paradigms for approaching assessment practices that align with critical practice. While this study presents the results of this process-learning outcomes for one of the frames-the intent is not to suggest that these learning outcomes are definitive or even transferable. Rather, this study suggests that by applying transformative research paradigms, and exploring methodologies that align with these paradigms, librarians might "fabulate" more critically aligned, authentic, and values-centered learning outcomes.

Concept Mapping

Broadly defined, concept mapping includes a variety of techniques to represent or visualize knowledge (Kane \& Trochim, 2006). Applications of concept mapping in library science predominately employ techniques first developed by Novak and his research team in the 1970s (Novak \& Cañas, 2006). This form of concept mapping, based in constructivist epistemology, was developed to "represent children's conceptual understanding and to be able to observe explicit changes in the concept" over time (Novak \& Cañas, 2006, p. 175). Within library science, this technique has been implemented as an instructional technique and, to a lesser extent, for planning and assessment (Colosimo \& Fitzgibbons, 2012).

This study employed a specific and distinct research methodology, which is also called concept mapping. While rooted in constructivist approaches, this form of concept mapping is a substantively different than Novak's (Cañas et al., 2003) in that it includes specific qualitative and quantitative methods, characterized as integrated mixed methods (Kane \& Trochim, 2006). It was developed by Trochim and Linton (1986) in response to the need for "methods which can help multiple constituency groups collaborate on the development of conceptual frameworks which can guide the planning and evaluation effort” (p. 289). This methodology has been used in a variety of fields and for a number of purposes including program development, organizational planning, needs assessment, and research agendas (Rosas \& Kane, 2012). The term concept mapping here refers to this specific research methodology.

Concept mapping includes three distinct components: (a) a focus group brainstorming session with the goal of generating an exhaustive list of statements related to a concept, (b) individual sorting and rating of the statements produced in the focus group by each study 
participant, and (c) mapping of both the sorted categories and rating of items to produce a visual representation that synthesizes individual responses (Trochim, 1989). This methodology allows for collaborative and expansive thinking about a chosen concept and for the visualization of both the connection between items and the relative importance (as perceived by participants) of groups of statements (Trochim, 1989; Trochim \& Linton, 1986).

\section{Theoretical Framework}

Concept mapping aligns well to challenges of transformation, group understanding, and identity. Sutherland and Katz (2005) asserted that concept mapping is rooted in cognitive learning and social processing theory and thus supports organizational learning, capacity building, and visioning. They concluded that concept mapping is a way to both attend to the social and learning needs of individuals and to produce new knowledge that leads to greater organizational understanding and practice.

Concept mapping also aligns well with the transformative research paradigm.

Transformative research paradigms, as articulated by Mertens, "recommend the adoption of an explicit goal for research to serve the ends of creating a more just and democratic society that permeates the entire research process" (2003, p. 159). This paradigm evolved from the work of researchers from various critical approaches seeking to bridge methodology and social justice values. Building on Mertens' work, Sweetman, Badiee, and Creswell (2010) operationalized ten characteristics, posed as questions, of transformative mixed methods research:

a) Do the authors openly reference a problem in a community of concern?

b) Do the authors openly declare a theoretical lens?

c) Were the research questions (or purposes) written with an advocacy stance?

d) Did the literature review include discussions of diversity and oppression?

e) Did the authors discuss appropriate labeling of the participants?

f) Did data collection and outcomes benefit the community?

g) Did the participants initiate the research, and/or were they actively engaged in the project?

h) Did the results elucidate power relationships?

i) Did the results facilitate social change? 
j) Did the authors explicitly state their use of a transformative framework? (pp. 442443)

Using these ten questions, this article concludes with a reflection on the extent to which concept mapping as a method for generating learning outcomes is a viable transformative approach.

\section{Methodology}

\section{Research Goals}

This study explored the viability of the concept mapping methodology to develop relevant and expansive learning outcomes for the Framework that might illuminate social justice and critical thinking. The explicit intent of this project was to explore this methodology, which might be replicated locally rather than to create a standardized set of learning outcomes. A secondary goal of this project was to experiment with collaborative processes for reenvisioning information literacy and pedagogical practice in libraries.

Study Setting

This study engaged a group of 11 academic librarians from across the United States in the fall and winter of 2015. Participants met virtually for two online focus groups and completed individual sorting and rating tasks.

\section{Participants}

Trochim (1989) suggested that a variety of sampling techniques may be used for participant selection. This study engaged participants based on their knowledge and experience rather than applying random or representative sampling. Participants for this study were all practicing librarians serving institutions of higher education in the United States. The principal investigator (PI) recruited librarians who had already demonstrated interest in and engagement with the Framework. Participants were identified based on their contributions to professional dialogue about the Framework on social media, at professional conferences, or at their local institutions. The PI identified a pool of potential participants by reviewing social media posts and professional conference programs, as well as seeking recommendations from library professionals. The PI contacted potential participants via email and followed up with a phone call to answer questions and gauge interest. 
The resulting participant group included 11 librarians from institutions across the continental United States. Institutions included a range of characteristics, including large, medium, and small FTE; private and public; secular and non-secular; and diverse student populations in terms of race, ethnicity, and economic background. Participants included librarians serving a variety of disciplines including humanities, STEM, and business, as well as the functional areas of assessment and first year experience.

\section{Procedures}

Most concept mapping applications begin with defining the construct to be examined (Kane \& Trochim, 2006; Trochim, 1989). In this case, the process through which the frames were developed, including the ongoing Delphi study upon which the Framework was inspired and the subsequent drafting, feedback, and review that shaped the final iteration of the Framework, was treated as analogous to this phase of the methodology. Thus, the frame "Information Has Value" was treated as a construct already defined by a group of stakeholders to which the research participants belonged.

Based on concept mapping methodology (Kane \& Trochim, 2006; Trochim, 1989), the PI followed this process:

1. facilitated a brainstorming focus group (conducted virtually) to develop learning outcome statements for the frame;

2. distributed the statements to participants with instructions for sorting and rating the items;

3. mapped the sorting and rating of statements using multidimensional scaling and hierarchical cluster analysis; and

4. conducted a follow-up virtual focus group for the participants to review and reflect on the map and the process.

This study used three software packages: Zoom web conferencing for virtual focus groups; usabiliTEST for card sorting exercises; and Qualtrics for rating learning outcomes. The study was conducted between June and November 2015. Recruitment was complete in June, and the first focus group was held in late August. The PI synthesized the statements, sent them to the group for feedback, and distributed the rating and sorting materials the week following the focus group. All participants completed rating and sorting within one week of receiving the materials. The final focus group was held in early November, with the draft concept map and statements sent the day before. 
The initial brainstorm focus group was conducted for 90 minutes. All participants joined a web conference call which allowed participants to view a shared screen. Participants were provided with ground rules for the session and a brief introduction to the tasks of the session. Based on Kane and Trochim (2006), instructions included basic brainstorming guidelines, with the task of generating as many statements as possible. Participants were encouraged to consider social justice and critical thinking elements of the frame, though these elements were not defined for participants. Participants were then presented with the session prompt:

What will students be able to do and know if they successfully internalize the threshold concept "Information has value"?

Because our purpose is to generate statements, we will use a statement format prompt to help us. The format we will be using is:

The student that has successfully incorporated the frame will....

During the session, participants generated over 100 outcome statements. The session was lively, engaging, and some participants felt they could have generated more statements. After the initial focus group, the PI synthesized the statements, removing redundancies, reformatting statements to align with typical outcomes statement format, and clarifying language where necessary. Furthermore, the PI reviewed the recording from the brainstorm focus group and added statements that were not documented during the session. The PI applied Bloom's taxonomy to ensure appropriate verbs were aligned with each statement. Statement synthesis resulted in 75 outcomes statements. This initial list was distributed to the group for optional review. Two participants provided feedback.

The finalized outcomes statements were formatted in Qualtrics and usabiliTEST. The Qualtrics survey included each outcome statement with the following instructions:

On this survey, each learning outcome statement is listed along with a Likert scale (from 0-10) of importance, where 0 indicates "Not Important at All" and 10 indicates "Extremely Important". Five (5) is the midpoint on this scale, indicating "Neither Important nor Unimportant." Rate each statement based on how important you feel it is as a learning outcome for the frame "Information Has Value."

Branch 
The usabiliTEST card sort included each statement on a "card" that could be moved to a display area to create groups of statements. Participants were provided instructions for sorting statements into groups based on their own determination of how best to organize the outcomes. The following guidelines for sorting (based on Kane \& Trochim, 2006, p. 72) were provided:

1. Each card can be placed in only one group.

2. There must be at least two groups.

3. Groups are allowed to contain one card.

4. All groups must have a title. Title the group whatever makes sense to you.

5. All cards must be in a group.

Instructions and links to both the survey and the card sort were sent to each participant. Once participants completed the rating and sorting exercises, the PI compiled the average rating and standard deviation (generated by Qualtrics) for each statement. The PI rendered the initial map using SPSS to create a multidimensional scale (MDS) of the sorted statements and manually identified boundaries around groups of statements. The group was convened for a final focus group to review the draft map and rating data, to identify key findings, and to reflect on the process.

Due to time constraints, the draft map created in SPSS was reviewed in the final focus group, even though the PI was still investigating some inconsistencies with the statement clusters. After the final focus group, the PI continued to develop the map and determined greater validity could be achieved by using the MDS and hierarchical cluster analysis of the statements generated by usabiliTEST. Using hierarchical cluster analysis to identify boundaries for clustered statements on the MDS, the PI created a cluster map and calculated the mean and standard deviation for each cluster. Additionally, the PI assigned individual cluster titles to each group by synthesizing the titles provided by participants and the general theme of the cluster. This mapping process illuminated both the group's collective thinking about which statements aligned as conceptual groups as well as how the group rated the importance of each cluster. This finalized map and set of statement clusters was sent to all participants after the final focus group.

\section{[ RESEARCH ARTICLE ]}




\section{Results}

In much of the literature related to concept mapping, the cluster map is created using a proprietary software that combines the elements of rating, multidimensional scaling and hierarchical cluster analysis. In this study, usabiliTEST generated both the MDS and the hierarchical cluster analysis that were then used by the PI to manually produce the final cluster map. This approach proved to be both cost-effective and accurate. Figure 1 shows the final concept map generated from this process.

\section{Figure 1}

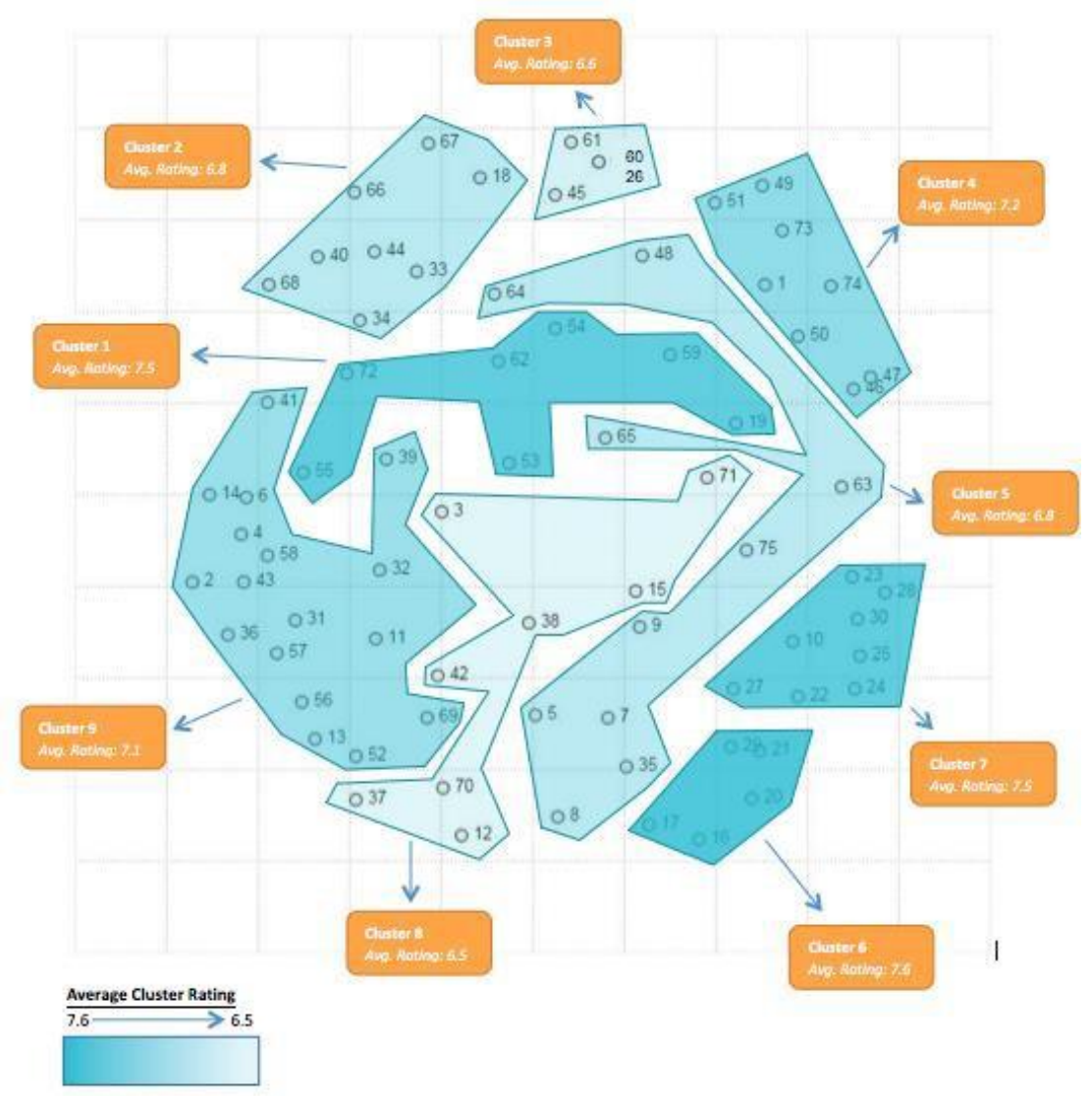

Each numbered point on this map represents a learning outcome statement, grouped with hierarchical cluster analysis. The relative saturation of each cluster represents the average cluster rating for importance. A larger version of this figure is available as an online supplementary file.

Each participant independently created and assigned a title to their groups of statements. The PI reviewed the independently generated group names and assigned titles relevant to the emergent cluster. Table 1 summarizes the cluster names, an example outcome

\section{Branch}


statement, its average rating, and the standard deviation per cluster. A complete list of learning outcome statements grouped by cluster is available as an online supplementary file.

Table 1 - Learning Outcome Clusters and Sample Statements

\begin{tabular}{|l|l|l|l|}
\hline Cluster & Example Learning Outcome Statement & M & SD \\
\hline $\begin{array}{l}\text { 1. Value of } \\
\text { Information } \\
\text { Communities }\end{array}$ & $\begin{array}{l}\text { analyze how access to information impacts the } \\
\text { ability to participate in communities of } \\
\text { discourse }\end{array}$ & 7.5 & $\mathbf{1 . 9}$ \\
\hline $\begin{array}{l}\text { 2. Scholarly } \\
\text { Conventions of } \\
\text { Value }\end{array}$ & $\begin{array}{l}\text { critique traditional systems of assigning value } \\
\text { to information in specific disciplines }\end{array}$ & 6.8 & $\mathbf{2 . 5}$ \\
\hline $\begin{array}{l}\text { 3. Access \& } \\
\text { Navigation }\end{array}$ & $\begin{array}{l}\text { demonstrate facility in navigating systems of } \\
\text { information to meet information needs }\end{array}$ & 6.6 & $\mathbf{2 . 5}$ \\
\hline $\begin{array}{l}\text { 4. Formal } \\
\text { Recognition of } \\
\text { Value }\end{array}$ & $\begin{array}{l}\text { recognize their own rights related to copyright } \\
\text { and intellectual property }\end{array}$ & 7.2 & $\mathbf{2 . 2}$ \\
\hline $\begin{array}{l}\text { 5. Access(ibility) is } \\
\text { Power }\end{array}$ & $\begin{array}{l}\text { analyze how "gift" and "monetary" approaches } \\
\text { to distributing information impact access }\end{array}$ & 6.8 & $\mathbf{2 . 4}$ \\
\hline $\begin{array}{l}\text { 6. Information } \\
\text { Privilege }\end{array}$ & $\begin{array}{l}\text { appraise their own and others' information } \\
\text { privilege and marginalization }\end{array}$ & 7.6 & $\mathbf{2 . 1}$ \\
\hline $\begin{array}{l}\text { 7. Information is } \\
\text { Power(ful) }\end{array}$ & $\begin{array}{l}\text { interpret how issues of power are reflected in } \\
\text { the historical record/narrative }\end{array}$ & 7.5 & $\mathbf{2 . 1}$ \\
\hline $\begin{array}{l}\text { 8. Information } \\
\text { Agency \& } \\
\text { Responsibility }\end{array}$ & $\begin{array}{l}\text { apply and defend personal judgement for } \\
\text { assessing the value of information }\end{array}$ & 6.5 & $\mathbf{2 . 9}$ \\
\hline $\begin{array}{l}\text { 9. Systems of Value } \\
\text { interpret how value systems related to } \\
\text { information are dynamic and can fluctuate }\end{array}$ & 7.1 & $\mathbf{2 . 3}$ \\
\hline
\end{tabular}

Average cluster ratings ranged from a high of 7.5 to a low of 6.5. All clusters rated above the midpoint of the scale, likely because the statements were generated by the same group that rated them. Interestingly, the highest rated cluster "Value of Information Communities" had the lowest standard deviation (1.9), indicating the group showed the most consistency in rating the importance of the learning outcome statements from this cluster as compared to others. In mirror image, the lowest rated cluster "Information Agency \& Responsibility" had the highest standard deviation (2.9), indicating that the group had the most variation in how they rated statements in this cluster. The group rated clusters dealing with issues of power 
and critical thinking the highest and those dealing with more skill-based tasks, such as citation and information retrieval, the lowest.

To conclude this process, the group convened for a final focus group in which all but one participant attended. During this meeting, the group reviewed the draft cluster map, the average ratings/standard deviation for clusters, and reflected on the process. A few findings emerged from this discussion:

- Variation in ratings may have been the result of several factors. Rather than overall importance, participants in some cases rated a statement low because they felt it was less well aligned with the frame under consideration. Others rated a statement lower in thinking about a specific audience (generally undergraduates) and what might reasonably be expected from them. In other instances, statements were rated based on perceived overall importance. In still other cases, the learning outcome statement may have been rated low for being convoluted and difficult to interpret.

- The group felt the process was highly successful and several expressed that they were invigorated by participating.

- One participant expressed concerns about the applicability of the learning outcomes statements, specifically, that they may not be useful to others and may not represent some divergent ideas about the frame.

\section{Discussion}

This project proved to be a highly successful example of applying values-based and transformative approaches to learning outcomes development. The participants, by and large, felt the process resulted in a meaningful set of learning outcomes that stretched the potential of the frame to address both standard information literacy skills and explicit critical, social justice-related aspects of information literacy. Furthermore, the resulting learning outcomes and the process itself proved to align with the transformative research paradigm: participants were engaged in a collaborative process and the results directly address information literacy and social impact.

This process might support library instructors in adopting an advocacy stance in direct response to critiques of current assessment practices in higher education. Processes that facilitate local and meaningful engagement with learning outcomes development may provide a basis for librarians to advocate for more values-based assessment that is aligned with the core tenets of higher education as a common good. While standards, as Drabinski 
and Sitar (2016) argued, may connote institutional power, collaboration and broader engagement with faculty, staff, and students outside of the library to develop or integrate local learning outcomes may also serve this end while demonstrating the library's potential as advocates for assessment practices that are values-based and that resist neoliberal orientations.

This process also proved to be both time and cost effective. Participants spent a total of two and a half hours in focus group discussions to generate and review the statements. The average completion time for the rating of statements was 15 minutes. While time estimates for completion of the sorting exercise was not recorded by the software used for this task, all participants completed the sorting and rating exercises within the established timeline. Qualtrics provides free accounts and usabiliTEST offers low-cost monthly subscriptions. Although Zoom does not offer free administrative accounts, other free or low-cost options for video conferencing are readily available.

There are several potential applications of this methodology for exploring the Framework further. First, this study suggests a viable approach to local implementation. Campuses might explore this methodology with faculty members or students in alignment with the transformative paradigm. This might include developing a timeline for prioritizing and working through each of the frames. This approach might also be implemented within interest groups or roundtables in the larger profession and might yield interesting results. For example, the ACRL Women \& Gender Studies Section or the Joint Council of Librarians of Color might explore learning outcomes for the Framework, intentionally focusing on the specific interests and concerns of those groups.

In addition to developing learning outcomes, concept mapping might be a viable method to continue developing the Framework itself. Recognizing the limitations of the Framework, some librarians are currently exploring adding additional frames, for example, the frame referenced earlier-Information as a Human Right (Battista et al., 2015). Concept mapping might be a useful approach to develop new frames or to explore locally developed frames. Finally, learning outcomes are a beginning and should directly connect to instruction and assessment. Further exploration of the use of these learning outcomes in both design of instruction and assessment of student work will help establish their utility in an academic setting. While the large number of learning outcomes produced by this process may seem unwieldy, clusters provide a useful way to select a smaller subset of learning outcomes to tie 
to instruction and assessment. Additional research might explore approaches to formative and summative assessment of student learning related to a select group of learning outcomes.

\section{Limitations}

There are several limitations of this study that should be addressed in local applications. First, while the participant pool was not meant to be representative, the sample intentionally included participants who were already supportive of the Framework. While local applications might draw on local experts, one might expect more variation in overall support or knowledge of the Framework. In the local context, participants may need to collaboratively explore the Framework in advance of implementing this methodology.

A valid critique raised in the final focus group of this study concerned the representativeness of the learning outcomes. A participant raised the concern that the statements produced might not include divergent ideas about the Framework and the particular frame under consideration. While this study was not intended to produce the learning outcomes for the frame but rather a set of learning outcomes relevant to those who produced them, this critique is worth noting. If this study were reproduced, it would likely have very different outcomes, character, and ideas that are relevant and inclusive of the local population. This is not to say that the learning outcomes generated by this process would not be relevant beyond the participant group but rather that they do not need to be.

The final concept map analysis and focus group also revealed two core recommendations for improving this process. First, the initial brainstorm may have benefitted from being longer. Participants felt that they could have generated even more statements than they did and that some areas could have been covered more deeply with additional time. Second, in the interest of not over-burdening the participant group, the PI synthesized the statements. While this approach was appropriate for this exploration, the process would be strengthened by an additional focus group after the initial generation of statements to (a) check for alignment of statements to the concept, including removing statements that might fit better with another frame; (b) clarify convoluted language; and (c) engage in finalizing the statements, particularly in exploring appropriate action verbs for each statement.

Branch 


\section{Conclusion}

Returning to the transformative mixed methods paradigm, this study demonstrates that concept mapping is a methodology that can be carried out to align with many or all of the ten characteristics outlined by Sweetman et al. (2010). These characteristics were applied to this study, as described below. The correlating questions $(\mathrm{a}-\mathrm{j})$ (listed in the literature review section above) are indicated in parentheses.

In this study, the research was undertaken to address a particular problem in a community of concern (a). Within the transformative paradigm, community of concern references the study and engagement of disenfranchised groups (Mertens, 2003). While librarians may not demographically present as a marginalized group, concern about academic librarians' status, standing, and identity within the hierarchy of the academy has been raised in the literature (Accardi, 2009; Pagowsky, 2015). The elements of diversity, oppression, and social justice (c, $\mathrm{h}, \& \mathrm{~d}$ ) are also evident within the research goals, the framing of the focus group, and the literature review of this study. The explicit theoretical stances of critical information literacy and the transformative paradigm were employed ( $b$ \& $j$ ) to bring forth issues of social justice, emancipatory education, and democratic society. While the benefits of this study for the larger community are not immediately known, the positive experience described by the participant group indicates that this study provided them with a meaningful experience $(f)$ and that participants were actively engaged, almost as research partners (g). Additionally, this model is designed with the aim of facilitating social change by advancing values-focused assessment practices (i).

Embracing transformative research paradigms and applying new methodologies to support these approaches holds great potential to address the concerns and challenges this article proposed. The PI sought to explore how a methodological process that draws on critical theory can provide librarians with models for actualizing the opportunity to re-envision information literacy that the Framework presents. Therefore, this study does not advance concept mapping as the definitive methodology for achieving this goal, but rather it encourages librarians to explore methodologies that align with transformative paradigms and that hold promise for developing viable local learning outcomes. Furthermore, transformative methods, when applied to learning outcomes for the Framework, may provide a means by which librarians can participate in the larger movement to reclaim assessment as "an ethical, value concerned social practice" (Wall et al., 2014, p. 5). 


\section{Acknowledgements}

The author would like to acknowledge the leaders, faculty, and cohort members from the Institute for Research Design in Librarianship (IRDL), where this project was first incubated, and, above all, the anonymous participants of this project, who were true collaborators, partners, and visionaries.

\section{References}

Accardi, M. T. (2009). Teaching against the grain: Critical assessment in the library classroom. In M. T. Accardi, E. Drabinski, \& A. Kumbier (Eds.), Critical library instruction: Theories and methods (pp. 251-264). Duluth, MN: Library Juice Press.

Association of College \& Research Libraries. (2000). Information literacy competency standards for higher education. Retrieved from https://alair.ala.org/handle/11213/7668

Association of College \& Research Libraries. (2015). Framework for information literacy for higher education. Retrieved from http://www.ala.org/acrl/standards/ilframework

Battista, A., Ellenwood, D., Gregory, L., Higgins, S., Lilburn, J., Harker, Y. S., \& Sweet, C. (2015). Seeking social justice in the ACRL Framework. Communications in Information Literacy, 9(2), 111-125. https://doi.org/10.15760/comminfolit.2015.9.2.188

Cañas, A. J., Coffey, J. W., Carnot, M. J., Feltovich, P., Hoffman, R. R., Feltovich, J., \& Novak, J. D. (2003). A summary of literature pertaining to the use of concept mapping techniques and technologies for education and performance support (Report to the Chief of Naval Education and Training). Retrieved from https://www.ihmc.us/users/acanas/Publications/ConceptMapLitReview/IHMC\%20Lite rature\%20Review\%20on\%20Concept\%20Mapping.pdf

Colosimo, A., \& Fitzgibbons, M. (2012). Teaching, designing, and organizing: Concept mapping for librarians. Partnership: The Canadian Journal of Library and Information Practice and Research, 7(1). https://doi.org/10.21083/partnership.v7i1.1800

Dalal, H. (2015, January 7). An open letter regarding the Framework for information literacy for higher education [Blog post]. Retrieved from https://acrlog.org/2015/01/07/an-openletter-regarding-the-framework-for-information-literacy-for-higher-education/

Branch

Illuminating Social Justice in the Framework 
Dempsey, M. E., Dalal, H., Dokus, L. R., \& Charles, L. H., \& Scharf, D. (2015). Continuing the conversation: Questions about the Framework. Communications in Information Literacy, 9(2), 164-175. https://doi.org/10.15760/comminfolit.2015.9.2.193

Drabinski, E., \& Sitar, M. (2016). What standards do and what they don't. In N. Pagowsky \& K. McElroy (Eds.), Critical library pedagogy handbook (Vol. 1, pp. 53-64). Chicago: Association of College and Research Libraries. Retrieved from https://digitalcommons.liu.edu/brooklyn_libfacpubs/25

Elmborg, J. (2006). Critical information literacy: Implications for instructional practice. Journal of Academic Librarianship, 32(2), 192-199. https://doi.org/10.1016/j.acalib.2005.12.004

Foasberg, N. M. (2015). From standards to frameworks for IL: How the ACRL Framework addresses critiques of the Standards. portal: Libraries and the Academy, 15(4), 699-717. https://doi.org/10.1353/pla.2015.0045

Gardner, C. C., \& Halpern, R. (2016). At odds with assessment: Being a critical educator in the academy. In N. Pagowsky \& K. McElroy (Eds.), Critical library pedagogy handbook (Vol. 1, pp. 41-51). Chicago: Association of College and Research Libraries.

Kane, M., \& Trochim, W. M. K. (2006). Concept mapping for planning and evaluation. Thousand Oaks, CA: SAGE.

Mertens, D. M. (2003). Mixed methods and the politics of human research: The transformative-emancipatory perspective. In A. Tashakkori \& C. Teddlie (Eds.), Handbook of mixed methods in social and behavioral research (pp. 135-164). Thousand Oaks, CA: SAGE.

Novak, J. D., \& Cañas, A. J. (2006). The origins of the concept mapping tool and the continuing evolution of the tool. Information Visualization, 5(3), 175-184.

https://doi.org/10.1057/palgrave.ivs.9500126

Oakleaf, M. (2014). A roadmap for assessing student learning using the new Framework for information literacy for higher education. Journal of Academic Librarianship, 5(40), 510-514. https://doi.org/10.1016/j.acalib.2014.08.001

Pagowsky, N. (2015). A pedagogy of inquiry. Communications in Information Literacy, 9(2), 136-144. https://doi.org/10.15760/comminfolit.2015.9.2.190 
Rosas, S. R., \& Kane, M. (2012). Quality and rigor of the concept mapping methodology: A pooled study analysis. Evaluation and program planning, 35(2), 236-245.

https://doi.org/10.1016/j.evalprogplan.2011.10.003

Sutherland, S., \& Katz, S. (2005). Concept mapping methodology: A catalyst for organizational learning. Evaluation and Program Planning, 28(3), 257-269. https://doi.org/10.1016/j.evalprogplan.2005.04.017

Sweetman, D., Badiee, M., \& Creswell, J. W. (2010). Use of the transformative framework in mixed methods studies. Qualitative Inquiry, 16(6), 441-454.

https://doi.org/10.1177/1077800410364610

Tewell, E. (2015). A decade of critical information literacy: A review of the literature. Communications in Information Literacy, 9(1), 24-43. https://doi.org/10.15760/comminfolit.2015.9.1.174

Trochim, W. M. K. (1989). An introduction to concept mapping for planning and evaluation. Evaluation and Program Planning, 12(1), 1-16. https://doi.org/10.1016/0149$\underline{7189(89) 90016-5}$

Trochim, W. M. K., \& Linton, R. (1986). Conceptualization for planning and evaluation. Evaluation and Program Planning, 9(4), 289-308. https://doi.org/10.1016/0149$\underline{7189(86) 90044-3}$

Wall, A. F., Hursh, D., \& Rodgers, J. W., III. (2014). Assessment for whom: Repositioning higher education assessment as an ethical and value-focused social practice. Research $\mathcal{E}$ Practice in Assessment, 9(Summer), 5-17. Retrieved from https://www.rpajournal.com/assessment-for-whom-repositioning-higher-educationassessment-as-an-ethical-and-value-focused-social-practice/

\section{Branch}

Illuminating Social Justice in the Framework 